\title{
Stimulation of ovarian follicle growth after AMPK inhibition
}

\author{
Xiaowei $\mathrm{Lu}^{1,2, *}$, Song Guo ${ }^{1, *}$, Yuan Cheng² ${ }^{2}$ Jae-hong Kim², Yi Feng ${ }^{2}$ and Yun Feng ${ }^{1}$ \\ ${ }^{1}$ Department of Obstetrics and Gynecology, Center of Reproductive Medicine, Ruijin Hospital, Shanghai Jiao Tong \\ University School of Medicine, Shanghai, China and ${ }^{2}$ Department of Obstetrics and Gynecology, Stanford \\ University School of Medicine, Stanford University, Stanford, California, USA
}

Correspondence should be addressed to X Lu or Y Feng; Email: ssmuirl@163.com or artruijinyunfeng@163.com

*(X Lu and S Guo contributed equally to this work)

\begin{abstract}
Previous studies showed that the protein kinase B (Akt)-mammalian target of rapamycin (mTOR) and Hippo signaling Yes-associated protein (YAP) pathways play important roles in promoting follicle growth. Additionally, other studies demonstrated that $5^{\prime}$ adenosine monophosphate-activated protein kinase (AMPK) is an upstream regulatory element of mTOR and YAP. Here, we used AMPK inhibitor (Compound C) to in vitro cultured ovaries from 10-day-old mice followed by in vivo grafting into adult hosts or to in situ treated ovaries of 3-week-old mice by intrabursal injection followed by gonadotropin stimulation. We found that the phosphorylation of ovarian mTOR and downstream proteins (ribosomal protein S6 (S6) and eukaryotic translation initiation factor 4B (eIF4B)) was upregulated following Compound $\mathrm{C}$ administration, whereas tuberous sclerosis complex 2 (TSC2) phosphorylation was downregulated. Additionally, treatment with Compound C increased hypoxia-inducible factor 1-alpha (Hif1a), vascular endothelial growth factor A (Vegfa), VEGF receptor 2 (Vegfr2) and connective tissue growth factor (Ctgf) mRNA levels. Furthermore, treatment of 10-day-old mice with Compound C promoted the growth of preantral and antral follicles accompanied by enhanced angiogenesis. In situ intrabursal injection with Compound C, followed by controlled ovarian hyperstimulation, increased the number of ovulated oocytes in 3-week-old mice, and these oocytes could be successfully fertilized, leading to the delivery of healthy pups. Our results demonstrated that treatment with AMPK inhibitor resulted in the activation of the mTOR signaling pathway, increases in Ctgf expression in mouse ovaries, stimulation of follicle development and promotion of ovarian angiogenesis for ovary growth.

Reproduction (2017) 153 683-694
\end{abstract}

\section{Introduction}

The ovarian follicle is an essential functional unit of the mammalian ovary. Previous studies on follicle development mainly focused on the early antral-topreovulatory stages regulated by gonadotropin (Fauser \& Van Heusden 1997, Richards 1980, Hsueh et al. 1984). However, few studies have focused on hormonal regulation of preantral follicle growth, including how to activate dormant primordial follicles and promote primary and secondary follicles to the early antral stage (Li et al. 2010, Kawamura et al. 2013, Cheng et al. 2015). The regulatory mechanisms associated with preantral follicles are directly related to the treatment and prognosis of patients exhibiting ovarian dysfunctions, including primary ovarian insufficiency, poor ovarian response to follicle-stimulating hormone (FSH) stimulation and low ovarian reserve, as well as cancer and those with cryopreserved ovarian tissues. Particularly for patients with primary ovarian insufficiency, the ability to activate primordial follicles is directly related to determining their ability to produce genetic descendants (Kawamura et al. 2013).
Although it remains unclear what specific hormonal factors are involved in the activation of primordial follicles, recent studies showed that the protein kinase $B$ (Akt)-mammalian target of rapamycin (mTOR) signaling pathway plays an important role (Reddy et al. 2008, Jagarlamudi et al. 2009). mTOR is a serine/threonine kinase that integrates growth signals at the cellular level (Perl 2015), and treatment with an mTOR activator promotes follicle growth (Cheng et al. 2015). Moreover, the Hippo signaling pathway is essential for organismsize management, which is conserved in all metazoan animals (Pan 2007, Zhang et al. 2009, Halder \& Johnson 2011, Hergovich 2012, Piccolo et al. 2014, Hansen et al. 2015). Disruption of Hippo signaling increases the expression of nuclear Yes-associated protein (YAP) and downstream connective tissue growth factor (CTGF) (de Winter et al. 2008), which results in CTGF stimulation of cell growth, survival and proliferation (Holbourn et al. 2008). These findings led to improved outcomes in mouse or human ovaries and the subsequent birth of healthy babies (Kawamura et al. 2013).

$A$ recent study showed that the deletion of liver kinase B1 (LKB1) expression in mouse oocytes 
overactivated the primordial follicle pool through an Akt-independent LKB1-5' adenosine monophosphateactivated protein kinase (AMPK) pathway by downregulating AMPK expression continuously (Jiang et al. 2016). AMPK coordinates glucose and lipid metabolism in response to changes in nutrients and intracellular energy levels in all eukaryotes. In one study, AMPK activators inhibited the proliferation of ovarian theca-interstitial cells through an AMPKdependent mechanism (Will et al. 2012). Another study showed that AMPK activators decreased YAPdependent CTGF expression under cellular energy stress conditions, whereas AMPK depletion blocked this inhibitory effect (Mo et al. 2015). By contrast, AMPK inhibition activates the mTOR signaling pathway in tumors (Shackelford \& Shaw 2009). mTOR signaling activation promotes ovarian follicular development (Manning et al. 2002, Adhikari et al. 2009, 2010), and increased CTGF expression leads to ovarian follicle growth (Kawamura et al. 2013). Accordingly, we hypothesized that in vitro treatment with an AMPK inhibitor in a short term would activate primordial follicles and promote follicular development.

As the number of AMPK inhibitors is not so high, the best known one is Compound C. Its effect on inhibiting AMPK activation is confirmed when it was first mentioned as AMPK inhibitor in the literatures (Zhou et al. 2001, Kim et al. 2004, McCullough et al. 2005). It is a cell-permeable pyrrazolopyrimidine, which acts as a potent, selective, reversible and adenosine triphosphate-competitive AMPK inhibitor that was used to counteract the effect of AMPK activators, including 5-aminoimidazole-4-carboxamide ribonucleotide or metformin (Tang et al. 2011). It is the main tool for studying the role of AMPK activation in a variety of biological processes (Novikova et al. 2015). Treatment with Compound $\mathrm{C}$ reduces the phosphorylation of tuberous sclerosis complex 2 (TSC2) in cardiac hypertrophy cells or tumor cells and increases the phosphorylation of mTOR/ribosomal protein S6 kinase beta-1 (S6K1)/eukaryotic initiation factor 4E-binding protein 1 in vitro (Yi et al. 2015, Zhang et al. 2015, Zhao et al. 2015, Zhou et al. 2015), whereas S6K1 is the upstream regulatory element of ribosomal protein S6 (S6) and eukaryotic translation initiation factor 4B (elF4B) in tumorigenesis (Mamane et al. 2006). These findings confirmed that this drug might upregulate the expression of downstream proteins in the mTOR pathway; however, the differential effects of Compound $\mathrm{C}$ treatment in tumor and ovarian cells require verification.

Here, we aimed to investigate whether treatment with the AMPK inhibitor Compound $\mathrm{C}$ activates dormant follicles and promotes follicle development and vascularization in ovaries.

\section{Materials and methods}

\section{Animals}

CD-1 and C57BL/6 mice were purchased from Charles River Laboratories and housed in the animal facility of Stanford University under a 12-h light/darkness cycle with free access to water and food.

\section{Ethical approval}

Mice were treated in accordance with guidelines of the Stanford University Animal Research Committee, and the Stanford University Biosafety and Animal Research Committees approved all experimental protocols.

\section{Experimental design}

The details of the experimental design are illustrated in a flowchart in Supplementary Fig. 1 (see section on supplementary data given at the end of this article). The three experiments are described as follows.

\section{In vitro incubation of 10-day-old mouse ovaries (Experiment 1)}

Ovaries were extracted and transferred individually to culture plate inserts (Millipore) and cultured in $400 \mu \mathrm{L}$ Dulbecco's modified Eagle medium/F12 containing bovine serum albumin (Sigma-Aldrich), Albumax II (Invitrogen), insulin-transferrinselenium (Invitrogen), L-ascorbic acid and penicillinstreptomycin, which was an explant culture model described previously (Li et al. 2010, Cheng et al. 2015). The ovaries were randomly divided into several groups ( $n=5 /$ group) according to different concentrations $(0,3,10,30$ or $100 \mu \mathrm{M})$ or exposure times $(0,1,4,8,24$ or $96 \mathrm{~h})$ for incubation with Compound $\mathrm{C}$ (TOCRIS, Bristol, UK). The control ovaries $(0 \mu \mathrm{M}$ or $0 \mathrm{~h})$ were treated with vehicle only. Ovaries were cultured for 4 days, with changes of medium after 2 days to allow for weight determination. The Compound $\mathrm{C}$ powder was dissolved in dimethyl sulfoxide (DMSO; Sigma-Aldrich) to create a 100-mM stock, followed by dilution with culture medium prior to use.

\section{In vivo allograft of 10-day-old mouse ovaries} (Experiment 2)

Paired ovaries from the same CD-1 10-day-old donor were incubated with vehicle or Compound $\mathrm{C}$ for different drug exposure concentrations and times $(10 \mu \mathrm{M} / 1 \mathrm{~h}$, $n=10 ; \quad 10 \mu \mathrm{M} / 8 \mathrm{~h}, \quad n=5 ;$ or $30 \mu \mathrm{M} / 1 \mathrm{~h}, n=4)$, followed by grafting under separate sides of the kidney capsule in the same 9-week-old ovariectomized hosts. From 1 day after transplantation, hosts received daily intraperitoneal (i.p.) FSH injections (1 IU/animal) for 4 days as reported previously (Li et al. 2010, Cheng et al. 2015). The ovaries were collected 5 days after grafting for weight measurement. 
In situ intrabursal injection followed by controlled ovarian hyperstimulation (Experiment 3)

Immature 3-week-old C57BL/6 mice $(n=14)$ were separated into two groups randomly for ovarian intrabursal injection as described previously (Flesken-Nikitin et al. 2003). They received a single ovarian intrabursal injection with $10 \mu \mathrm{L}$ saline on the left side as a blank control and $10 \mu \mathrm{L}$ vehicle (the control group) or $50 \mathrm{ng} / 10 \mu \mathrm{L}(\approx 10 \mu \mathrm{M})$ Compound C (the treatment group) on the right side. After all of them received ovarian intrabursal injection and resuscitated from anesthesia, animals were then injected i.p. with $5 \mathrm{IU}$ equine chorionic gonadotropin (eCG), followed by an injection of $5 \mathrm{IU}$ human chorionic gonadotropin (hCG) after $48 \mathrm{~h}$. The ovulated oocytes in the two oviducts of each mouse were collected and counted after $16 \mathrm{~h}$, and ovaries were collected for weight determination and quantitative reverse transcription polymerase chain reaction (qRT-PCR). Meanwhile, the oocytes gained from the right sides were inseminated for in vitro fertilization and embryo transfer (IVF-ET) as described in previous studies (Kawamura et al. 2013, Cheng et al. 2015). In brief, oocytes were fertilized with sperm for $6 \mathrm{~h}$, and then cultured for development into blastocysts. And for embryo transfer, some Compound C-pretreated 2-cell stage embryos were transferred into oviducts of pseudopregnant, 8-week-old mice followed by pregnancy and delivery.

\section{Analyses after animal experimentation}

\section{Hematoxylin and eosin (H\&E) staining and follicle counting}

In vitro-cultured ovaries were treated with vehicle or $10 \mu \mathrm{M}$ Compound $\mathrm{C}$ and 8-h drug exposure time over a total 4-day culture prior to collection for H\&E staining. Grafted ovaries were in vitro cultured with vehicle or $10 \mu \mathrm{M}$ Compound $\mathrm{C}$ for $1 \mathrm{~h}$ followed by in vivo allograft and 4 days of $\mathrm{FSH}$ injection prior to collection. The ovaries ( $n=4 /$ group) were collected and fixed in $10 \%$ buffered formalin for 1 day, embedded in paraffin, serially sectioned $(4 \mu \mathrm{m})$ and stained with $\mathrm{H} \& \mathrm{E}$ for evaluation of follicle dynamics as previously described (Flaws et al. 1997, Vitt et al. 2000, Li et al. 2010). Briefly, every third section from each ovary was used for counting, and only follicles with clearly stained oocyte nuclei were counted to prevent recounting of the same follicle.

\section{CLARITY processing and immunofluorescence staining of whole ovaries}

Whole paired ovaries were in vitro cultured for $1 \mathrm{~h}$ with vehicle or $10 \mu \mathrm{M}$ Compound C, followed by in vivo allograft and 4 days of FSH injection and collection for CLARITY processing as described previously (Chung et al. 2013). Briefly, ovaries were immersed in 5-mL conical tubes containing 3-4 mL of hydrogel solution with $4 \%(\mathrm{w} / \mathrm{v})$ paraformaldehyde, $4 \%$ acrylamide, $0.05 \%$ bis-acrylamide, $0.25 \%$ VA-044, $0.05 \%$ Saponin and $1 \times$ phosphate-buffered saline (PBS) for 3 days at $4{ }^{\circ} \mathrm{C}$ (Chung et al. 2013). Tubes were then placed in a glass jar full of carbon dioxide to remove oxygen, followed by incubation in a $37^{\circ} \mathrm{C}$ water bath for $3 \mathrm{~h}$ to polymerize the hydrogel monomers.
Grafts were transferred into $10 \mathrm{~mL}$ clearing solution consisting of $200 \mathrm{mM}$ boric acid, 4\% (w/v) sodium dodecyl sulfate (SDS) dissolved in distilled $\mathrm{H}_{2} \mathrm{O}$ and supplemented with $\mathrm{NaOH}$ to reach pH 8.5 (Chung et al. 2013). The clearing solution was replaced two to three times per week until the ovaries became transparent at 8-10 weeks.

Transparent ovaries were moved into $10-\mathrm{mL}$ glass bottles containing PBST (PBS with $0.1 \%$ Triton-X) and shaken slowly for 1 day to remove residual SDS. Grafts were then incubated with primary antibodies (tyrosine hydroxylase (TH), 1:50, \#ab76442; and platelet and endothelial cell adhesion molecule 1/cluster of differentiation-31 (CD31), $1: 10$, \#ab28364; Abcam) for 2 days, washed in buffer for 1 day and incubated with secondary antibodies (Alexa FLUOR 488, 1:50, \#A11039; and Alexa FLUOR 594, 1:50, \#A11012; Thermo Scientific) for 2 days, followed by washing with buffer for 1 day. All procedures were conducted with shaking at $37^{\circ} \mathrm{C}$. Before imaging, ovaries were immersed in FocusClear solution (CelExplore, Taiwan, China) for $3 \mathrm{~h}$ to correct for refractive index. Images were obtained using a Leica SP5 confocal microscope (20x water-immersion objectives; numerical aperture: 1.0; working distance: $2.0 \mathrm{~mm}$; Leica Microsystems). The total ovarian areas and vascular areas of sections were measured by Image-J software (National Institutes of Health). Ovarian vascular area percentage was defined as the area of vascular extent (signals of CD31 fluorescence) to total ovarian area (total CD31 and TH fluorescence signals).

\section{Protein extraction and Western blot}

In vitro-cultured ovaries were collected after a 1-h exposure to Compound $\mathrm{C}$, followed by protein extraction using the Pierce BCA protein assay kit (Thermo Scientific) containing a protease-inhibitor cocktail and concentration determination. Protein samples were loaded onto a 4-12\% NuPAGE Bis-Tris gel (Invitrogen), and then transferred to polyvinylidene fluoride membranes. The membranes were subsequently incubated with primary antibodies for TSC2, mTOR, S6 and elF4B (Cell Signaling) and IRdye 800 rabbit secondary antibody (926-32211; LI-COR Biosciences, Lincoln, NE, USA) as previously described (Cheng et al. 2015). The primary antibodies are shown in Table 1. Images were collected using the LI-COR Odyssey infrared imager, and densitometry was performed using LI-COR Image Studio Lite, version 5.0 (LI-COR Biosciences).

\section{Real-time $q R T-P C R$}

In vitro-cultured ovaries were collected after $0-$, 1-, 4- or 8-h exposure to Compound C. Grafted ovaries were cultured with DMSO control or $10 \mu \mathrm{M}$ of Compound $\mathrm{C}$ for $1 \mathrm{~h}$ followed by in vivo allograft and 4 days of FSH injection prior to collection. In situ-treated ovaries from the right side of mice from each group were intrabursally injected with vehicle or Compound C, followed by controlled ovarian hyperstimulation. mRNAs were extracted using the Total RNA purification kit (\#37500; Norgen, Thorold, ON, Canada) according to manufacturer protocol, and cDNA was synthesized using the iScript cDNA synthesis kit (\#170-8891; Bio-Rad) prior to determining gene expression using the CFX96 Touch real-time PCR detection 
Table 1 Western blot antibodies used in this study.

\begin{tabular}{lcllc}
\hline Primary antibody & Product number & Specificity & Isotype & Dilution \\
\hline Phosphor-TSC2 & $\# 5584$ & Ser1387 & Rabbit & $1: 1000$ \\
TSC2 & $\# 4308$ & Total & Rabbit & $1: 1000$ \\
Phosphor-mTOR & $\# 5536$ & Ser2448 & Rabbit & $1: 1000$ \\
mTOR & $\# 2983$ & Total & Rabbit & $1: 1000$ \\
GAPDH & $\# 5174$ & Total & Rabbit & $1: 1000$ \\
Phospho-rpS6 & $\# 4858$ & Ser235/236 & Rabbit & $1: 1000$ \\
Phospho-elF4B & $\# 3591$ & Ser422 & Rabbit & $1: 1000$ \\
\hline
\end{tabular}

system (Bio-Rad). The primer sequences for hypoxia-inducible factor 1-alpha (Hif1a), vascular endothelial growth factor A (Vegfa), VEGF receptor 1 and 2 (Vegfr 1 and Vegfr 2 respectively), Ctgf and beta-Actin (Actb) were generated using the PrimerBlast tool (http://www.ncbi.nlm.nih.gov/tools/primer-blast/). Primer sequences are shown in Table 2. The relative gene expression data were analyzed by the $2^{-\Delta \Delta C T}$ method (Livak \& Schmittgen 2001), and Actb expression was used to normalize mRNA levels.

\section{Statistical analysis}

Results are presented as the mean \pm standard error of the mean (S.E.M.) of three or more independent assays. Statistical analyses were performed using Mann-Whitney $U$ and Kruskal-Wallis tests and a $P<0.05$ was considered statistically significant.

\section{Results}

\section{AMPK inhibition activates the $m$ TOR signaling pathway, increases Ctgf expression in the YAP signaling pathway and promotes ovarian growth in in vitro-cultured ovaries}

To investigate the effects of AMPK inhibition on the mTOR and YAP signaling pathways in ovarian tissue, ovaries from 10-day-old mice were incubated for $1 \mathrm{~h}$ with $10 \mu \mathrm{M}$ of Compound $\mathrm{C}$ prior to immunoblot analysis or 0 -, 1-, 4-, and 8-h treatment prior to mRNA quantitation. Ovarian phosphorylation of $\mathrm{mTOR}$ and downstream proteins (S6 and elF4B) rose transiently, whereas phosphorylation-TSC2 levels decreased after Compound $\mathrm{C}$ treatment (Fig. 1A). Additionally, mRNA levels of Hif1a and Vegfa associated with the mTOR downstream signaling pathway and Ctgf in the YAP signaling pathway were elevated after Compound $\mathrm{C}$ treatment for 1-4h (Fig. 1B).
Treatment with Compound C using an explant culture model led to both dose- and time-dependent increases in ovarian weights. As shown in Fig. 2A, ovarian weight increased as a gradient when the concentration of Compound $\mathrm{C}$ increased from $3 \mu \mathrm{M}$ to $30 \mu \mathrm{M}$, but decreased significantly at concentrations of $100 \mu \mathrm{M}$. Similarly, ovarian weight increased when the incubation time increased from $1 \mathrm{~h}$ to $8 \mathrm{~h}$, reaching a plateau at drug exposure times $>8 \mathrm{~h}$ (Fig. 2B). Therefore, higher doses of or longer exposure times to Compound $\mathrm{C}$ is not conducive to ovarian activation. Histological analyses (Fig. 2C and D) showed that the percentage of primordial follicles decreased in ovaries treated with $10 \mu \mathrm{M}$ Compound $\mathrm{C}$ for $8 \mathrm{~h}$, whereas the proportion of primary and secondary follicles increased, indicating the activation and growth of primordial follicles.

\section{AMPK inhibition promotes ovarian growth and strengthens microvascular development in grafted ovaries}

To determine whether in vitro-treated ovaries would continue growing after grafting into adult hosts, paired ovaries cultured with DMSO (vehicle control) or Compound $\mathrm{C}$ were transplanted under the kidney capsule of 9-week-old hosts. Graft weight significantly increased when pretreated with $10 \mu \mathrm{M}$ Compound $\mathrm{C}$ for $1 \mathrm{~h}$ or $8 \mathrm{~h}$, but no differences were observed between controls and groups treated with $30 \mu \mathrm{M}$ Compound $\mathrm{C}$ for $1 \mathrm{~h}$ (Fig. 3A). Additionally, the percentage of primordial follicles decreased in ovaries pretreated with $10 \mu \mathrm{M}$ Compound C, whereas primary, antral and preovulatory follicles increased (Fig. 3B and C). These results indicated that the follicles of ovaries pretreated with Compound $C$ continued to develop after in vivo grafting.

For further verification that AMPK inhibition promoted ovarian microvascular development, paired grafted ovaries pretreated with vehicle or Compound

Table 2 Target transcripts and primer sequences used for the quantification of mRNA levels in the ovaries.

\begin{tabular}{lll}
\hline Transcripts & Forward $\left(5^{\prime}-3^{\prime}\right)$ & Reverse $\left(5^{\prime}-3^{\prime}\right)$ \\
\hline Actb & GATGTGGATCAGCAAGCAGGA & AAACGCAGCTCAGTAACAGTC \\
Hif1a & TGCTGGCTCCCTATATCCCA & GTGCTCATACTTGGAGGGCT \\
Vegfa & GGAGTCTGTGCTCTGGGATTT & TGGCACGATTTAAGAGGGGA \\
Vegfr1 & CGTGCAAGGAACCTCAGACA & CGGAAGAAGACCGCTTCAGT \\
Vegfr2 & GATGCATTGTGCTGGCTCTG & CTGTGAAGAGCACGCAAACC \\
Ctgf & GTCAAGCTGCCTGGGAAATG & TGGGCCAAATGTGTCTTCCA \\
\hline
\end{tabular}


A
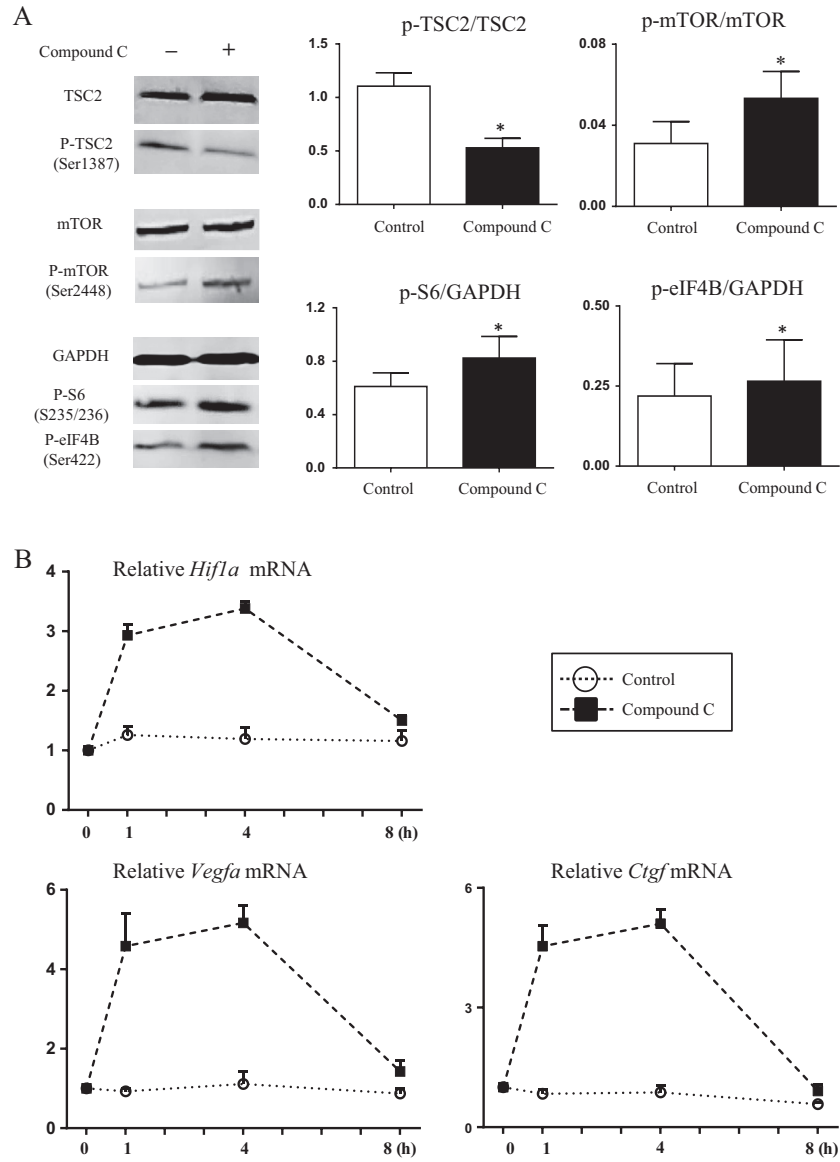

Figure 1 AMPK inhibition increases the expression of targets involved in the mTOR and YAP signaling pathways in in vitro-cultured mouse ovaries. (A) Ovaries of 10-day-old CD-1 mice were treated with DMSO (control) or Compound C $(10 \mu \mathrm{M})$ for $1 \mathrm{~h}$. Protein levels (TSC2, mTOR, S6 and elF4B) were analyzed by Western blot. Western blot quantification was undertaken using ImageJ software $\left(n=3\right.$; mean \pm S.E.M.). ${ }^{*} P<0.05$. (B) The relative mRNA expression (Hif1a, Vegfa and Ctgf) in in vitro-cultured 10-day-old mouse ovaries treated with DMSO (control) or Compound C $(10 \mu \mathrm{M})$ for different times $(0-8 \mathrm{~h})$. Relative gene expression in fresh ovaries collected from 10-day-old mice (no treatment) was used as the baseline in the graph (1.0), and Actb expression was used to normalize mRNA levels $(n=3 ;$ mean \pm S.E.M.; $P<0.001)$.

C were collected for CLARITY processing prior to immunohistochemistry staining and confocal scanning. We observed a larger number of preovulatory, but fewer primordial and primary follicles in the Compound C-pretreated group (Fig. 4A). Additionally, CLARITY processing revealed larger distributions of bright signals in endothelial cells in the surrounded area of each follicle, implying that AMPK inhibition intensified vascular development in grafted ovaries (Fig. 4A). The percentage of the vascular area also increased in the Compound C-pretreated group as compared with that observed in the control group (Fig. 4B). Furthermore, the expression of Hif1a, Vegfa, Vegfr2 and Ctgf mRNA in Compound C-pretreated ovaries was higher than that measured in the vehicle group; however, we observed no difference in Vegfr 1 mRNA levels (Fig. 4C). These results suggested that Compound $\mathrm{C}$ treatment stimulated in vivo follicle and blood vessel growth in grafted ovaries.

\section{AMPK inhibition increases ovulated oocytes after in situ injection}

To further investigate the in vivo effect of Compound C treatment, in situ ovarian intrabursal administration was performed. Although we observed no significant changes in ovarian weights after ovulation (Fig. 5A), the number of ovulated oocytes increased in Compound C-treated ovaries (Fig. 5B). Moreover, the expression of Htf1a, Vegfa, Vegfr2 and Ctgf mRNA in Compound C in situ-treated ovaries was higher than that observed in the vehicle group; however, we observed no difference in Vegfr 1 mRNA levels (Fig. 5C). In addition, the Compound C-pretreated oocytes could develop into blastocysts (Fig. 5D), had comparable rate of early embryonic development as compared with controls (Fig. 5E) and healthy pups were delivered (Fig. 5F).

\section{Discussion}

This study showed that AMPK inhibition followed by Compound C treatment-stimulated follicle development and promoted ovarian angiogenesis but only in a narrow range of drug dose. The effect of Compound $\mathrm{C}$ on ovarian growth is very sensitive to dose concentration and exposure time according to our results. A study showed that Compound $\mathrm{C}$ may be a potent AMPK-independent anti-glioma agent (Liu et al. 2014), whereas another paper pointed out that it may be an attractive candidate for anticancer drug development because it induces apoptosis in cancer cells (Dai et al. 2013). Although the mechanisms may be different between normal ovarian cells and cancer cells, those who tried to use it for clinical applications should be very careful.

Although its effect of AMPK inhibition has been confirmed in early studies (Zhou et al. 2001, Kim et al. 2004, McCullough et al. 2005), Compound C was also found to be an inhibitor of bone morphogenetic protein type 1 (BMP1) receptors ACTR-I (ALK2), BMPR-IA (ALK3) and BMPR-IB (ALK 6), which would affect embryogenesis and iron metabolism (Yu et al. 2007). BMP1 is highly conserved among different species (Maéno et al. 1993, Fukagawa et al. 1994, Bond \& Beynon 1995, Takahara et al. 1995, Lin et al. 1997, Reynolds et al. 2000). One study found out that BMP1 levels were stable in sheep granulosa cells, whereas its activity in follicular fluid decreased with follicular growth (Canty-Laird et al. 2010). Another study showed that BMP1 recombinant protein increased the expression of the key cell cycle regulators and decreased cell apoptosis pathway genes in in vitro-cultured buffalo 

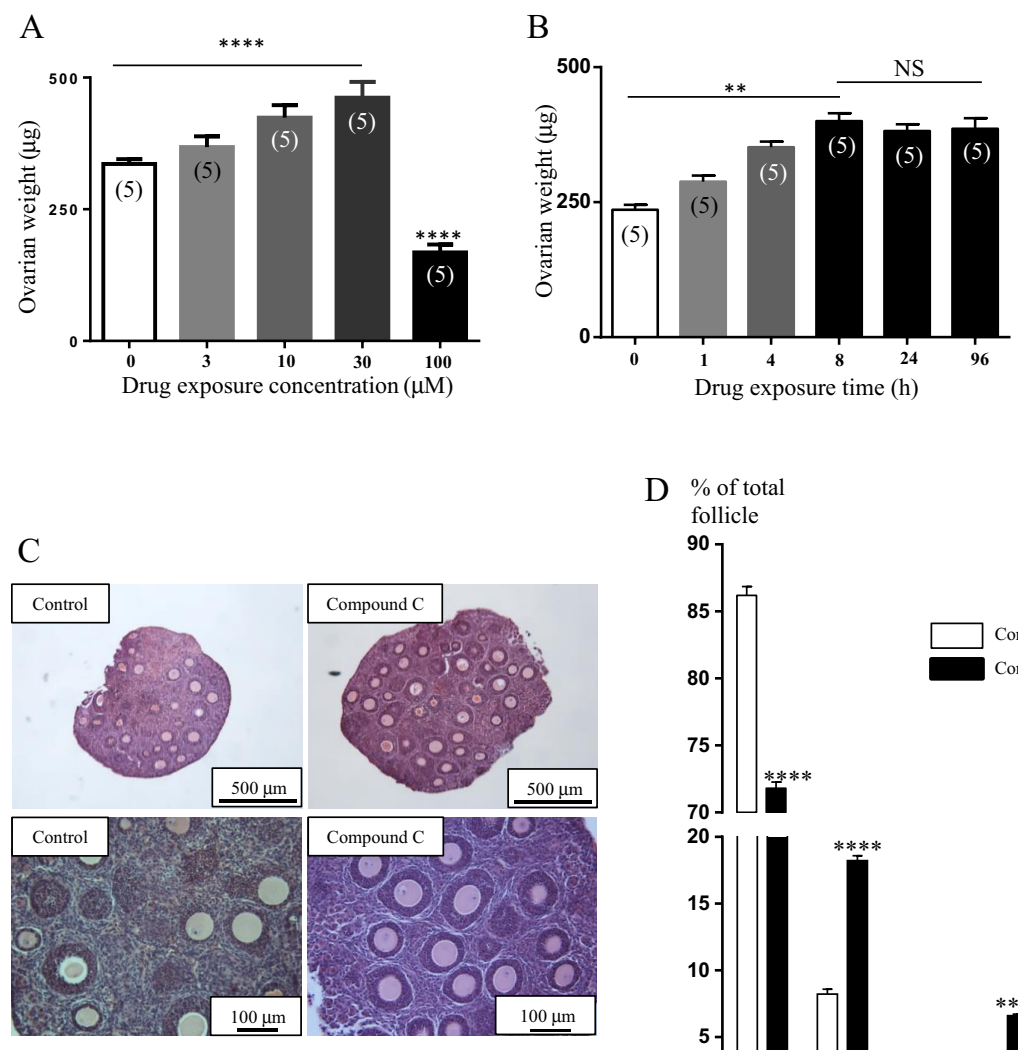

D $\%$ of total
follicle

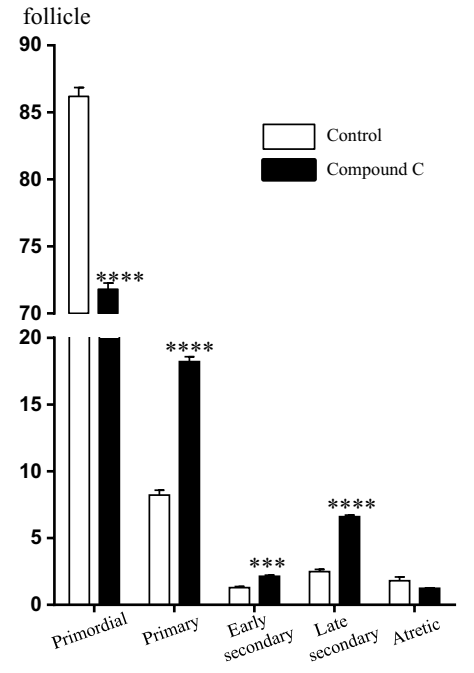

Figure 2 AMPK inhibition improves ovarian growth in vitro. (A) Ovaries from 10-day-old mice were treated with different doses of Compound $\mathrm{C}(0-100 \mu \mathrm{M})$ and incubated for 4 days, with medium changes after 2 days. Ovarian-explant weights were determined at the end of the culture $(n=5$; mean \pm S.E.M.). ${ }^{* * * *} P<0.0001$. (B) Ovaries from 10-day-old mice were treated with $10 \mu \mathrm{M}$ Compound $\mathrm{C}$ for different times (0-96h), washed twice and then incubated for 4 days with medium changes after 2 days. Ovarian-explant weights were determined at the end of culture $(n=5$; mean \pm S.E.M.). ${ }^{* * P}<0.01$. (C) Representative histologic sections of explants. Ovarian explants in the presence or absence of treatment with $10 \mu \mathrm{M}$ Compound $\mathrm{C}$ for $8 \mathrm{~h}$ and incubation for 4 days. (D) Distribution of follicles at different developmental stages in ovaries in the presence or absence of treatment with $10 \mu \mathrm{M}$ Compound $\mathrm{C}$ for $8 \mathrm{~h}$ $\left(n=4\right.$; mean \pm S.E.M.). ${ }^{* * *} P<0.001$; $* * * * P<0.0001$. granulosa cells (Lei et al. 2016). Anyway, there is no study about if Compound C will affect folliculogenesis through BMPs signaling till now. The preliminary data in our lab showed that the expression of $A / k 3$ was very low in mouse ovaries ( $\mathrm{Cq}$ value $\geq 35$ ), whereas $A l k 2$ and Alk6 mRNA levels increased short term after Compound $C$ treatment but had no significant change in graft ovaries and in situ treatment ovaries (Supplementary Fig. 2). Therefore, it may be another story with some unclear mechanisms, which we will try to figure out in the future.

The results of this study showed that AMPK inhibition activated the mTOR signaling pathway and increased YAP-dependent Ctgf expression in mouse ovaries. Additionally, our in vitro results indicated that AMPK inhibition decreased phosphorylation of TSC2 at Ser1387 and increased the expression of mTOR and downstream proteins. These findings were similar to results reported after selective disruption of LKB1 in mouse oocytes (Jiang et al. 2016) and conditional knockout of TSC1 in granulosa cells (Huang et al. 2013). Furthermore, we observed that mTOR activation stimulated dormant ovarian follicle growth through increased mTOR phosphorylation at Ser2448 similar to results reported after treatment with an $\mathrm{mTOR}$ activator (Cheng et al. 2015). We also observed an increased expression of downstream elF4B and S6 proteins after treatment with the AMPK inhibitor, similar to the results observed following treatment with an mTOR activator (Cheng et al. 2015). Activated mTOR signaling observed in primordial follicle granulosa cells also stimulates the secretion of stem-cell-factor ligand, activates the phosphoinositide-3-kinase (PI3K)-signaling pathway and stimulates dormant oocyte growth (Hsueh 2014, Zhang \& Liu 2015). Our results showed that AMPK inhibition resulted in increased primary and antral follicle growth and ovarian weight in in vitro-cultured and in vivo-grafted 10-day-old mouse ovaries, as well as elevated numbers of ovulated oocytes in 3-weekold mice. Therefore, treatment with an AMPK inhibitor promoted ovarian follicle development via an AMPKTSC2-mTOR-elF4B/S6 signaling pathway.

In addition, it had been previously demonstrated that FSH inhibited AMPK phosphorylation and promoted granulosa cell (Kayampilly \& Menon 2009, 2012) or Sertoli cell (Riera et al. 2012) proliferation, which means FSH may also promote ovarian growth via AMPK inhibition in a way similar to Compound $\mathrm{C}$, and this may help explain our results in in vivo allograft and in situ intrabursal injection models.

Hif1a is a downstream protein involved in the mTOR signaling pathway (Shackelford \& Shaw 2009, Perl 2015) 


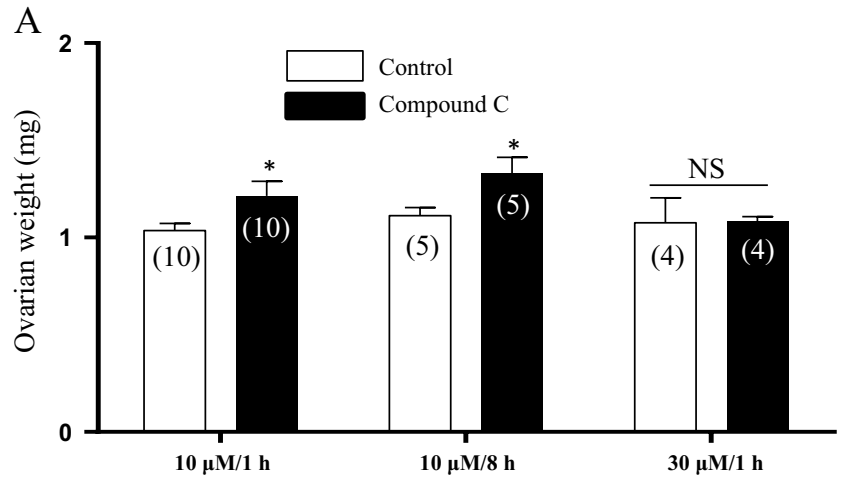

Drug exposure concentration/time

B

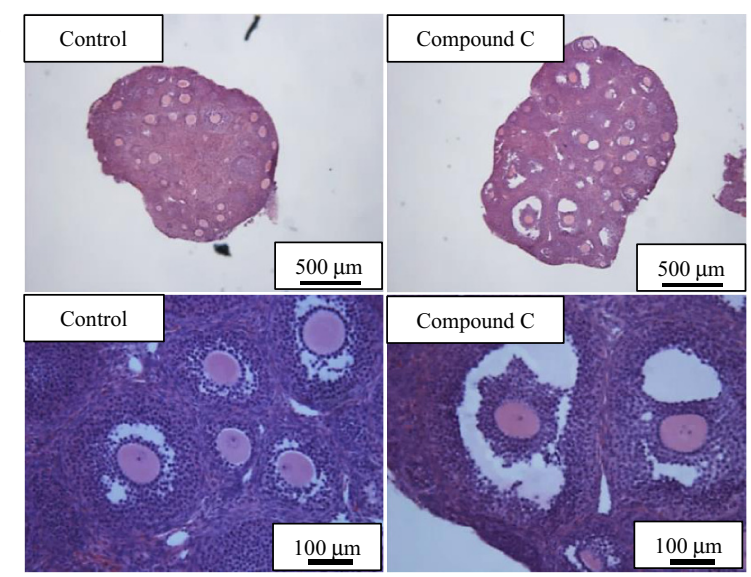

C

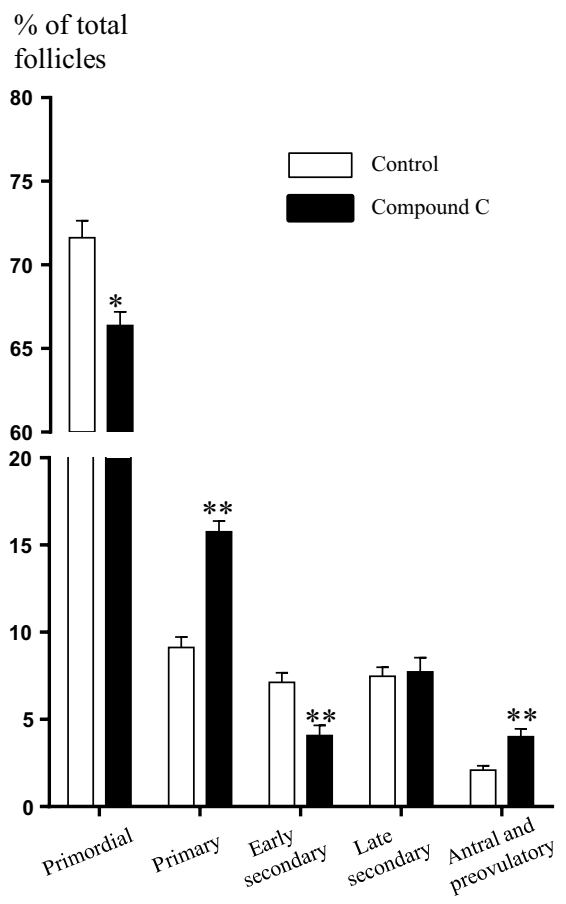

Figure 3 AMPK inhibition contributes to ovarian development in vivo. (A) Paired ovaries were treated with DMSO (control) or Compound $\mathrm{C}$ at different drug exposure concentrations and times (X-axis) prior to grafting into adult hosts treated daily with FSH for 4 days. After graft removal, graft weights were determined. Numbers that plays a critical role along with its target gene (Vegfa) in folliculogenesis and corpus luteum formation in mammalian ovaries (Yamamoto et al. 1997, Nishimura \& Okuda 2010, Rico et al. 2014, Wu et al. 2015, Yalu et al. 2015). Additionally, Hif1a activity is required for gonadotropin-regulated Vegfa expression and follicle growth (Rico et al. 2014). Vegfa expression constitutes a marker indicating ovarian function status where strong Vegfa expression in the presence of drug treatment or transcription factors suggests their effectiveness at stimulating follicle development (Joo et al. 2010, Park et al. 2011, 2013, Scotti et al. 2011, Choi et al. 2012). Here, treatment with an AMPK inhibitor increased mRNA levels of Hif1a, Vegfa and Vegfr2, enhanced CD31-signal intensity in the surrounded area of follicles and increased the vascular area percentage in treated ovaries. These results indicated that AMPK inhibition promoted blood vessel and follicle growth in mammalian ovaries.

We used a recently developed CLARITY method (Chung et al. 2013, Tomer et al. 2014) to evaluate the ovarian vascular function rather than using traditional sliced tissue, followed by immunohistochemistry staining. The CLARITY approach causes intact tissues to become transparent, thereby enabling immunostaining of markers to elucidate detailed structures from whole organs (Chung et al. 2013). Our results revealed that the control groups consisted primarily of primordial, primary and early secondary follicles, whereas late secondary and antral follicles were observed in the treated groups. This result agreed with those derived from H\&E staining. Additionally, we observed the formation of a bright, network-like structure based on CD31 signal intensity in the treated ovaries, indicating active ovarian angiogenesis and promotion of follicular development in Compound C-treated ovarian grafts. This finding also confirmed qRT-PCR results showing increases in Vegfa and Vegfr2 mRNA levels in the treated group.

We also observed that Vegfr 2 mRNA levels increased in treated ovaries in both the grafted and in situ injection groups, whereas no significant change in Vegfr 1 mRNA levels was observed in the control groups. This may be a consequence of their different functions. Vegfr 1 is primarily expressed in the blood cells and regulates the recruitment of hematopoietic stem cells and migration of monocytes and macrophages (Shibuya 2006). However, Vegfr2 is the principal mediator of Vegfa in endothelial cells, the binding of which activates intracellular signaling cascades that result in cell proliferation, migration, survival and increased permeability

in parentheses indicate the number of grafts used (mean \pm S.E.M.). ${ }^{*} P<0.05$. (B) Representative histologic sections of grafts. Paired ovaries were treated with DMSO (control) or $10 \mu \mathrm{M}$ Compound $\mathrm{C}$ for $1 \mathrm{~h}$ before grafting into adult hosts treated daily with $\mathrm{FSH}$ for 4 days. (C) Follicle dynamics of paired grafts exposed to DMSO or $10 \mu \mathrm{M}$ Compound $\mathrm{C}$ for $1 \mathrm{~h}\left(n=4 ;\right.$ mean \pm S.E.M.). ${ }^{* *} P<0.01 ; * * * P<0.001$. 

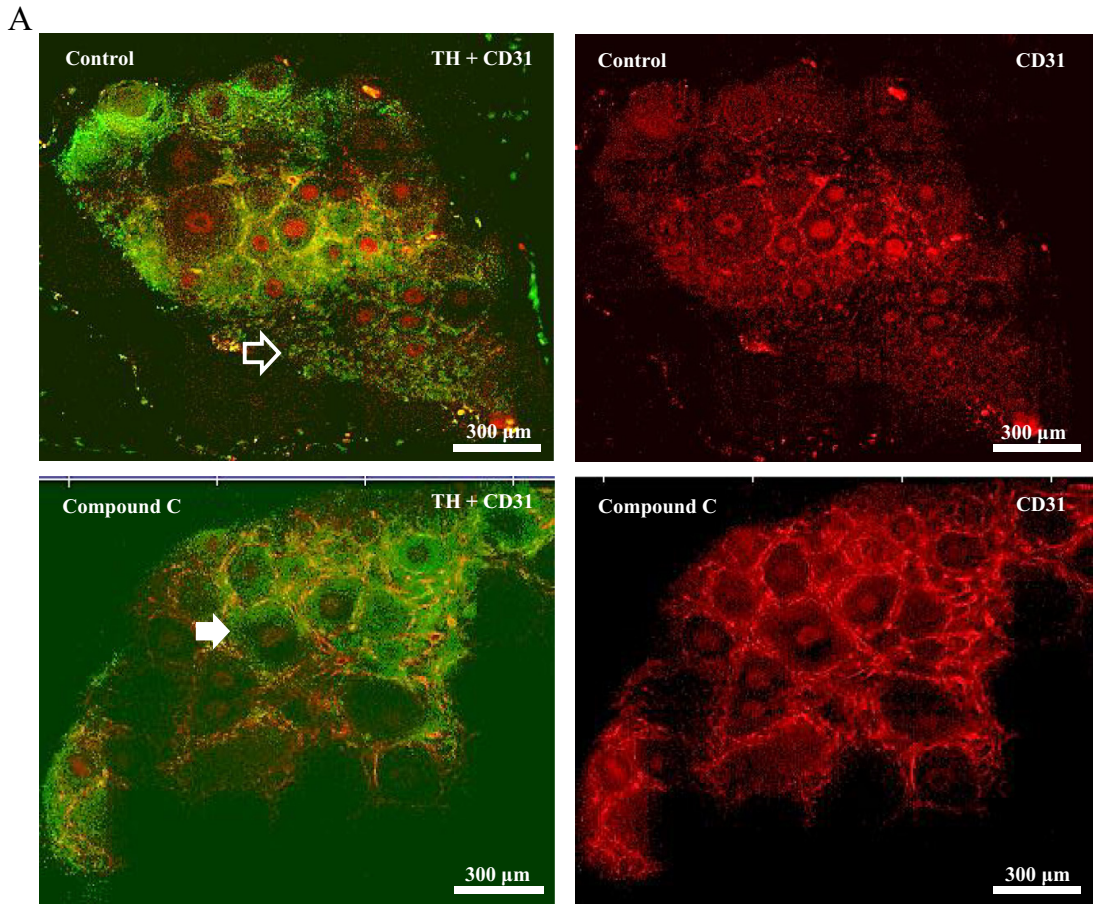

B
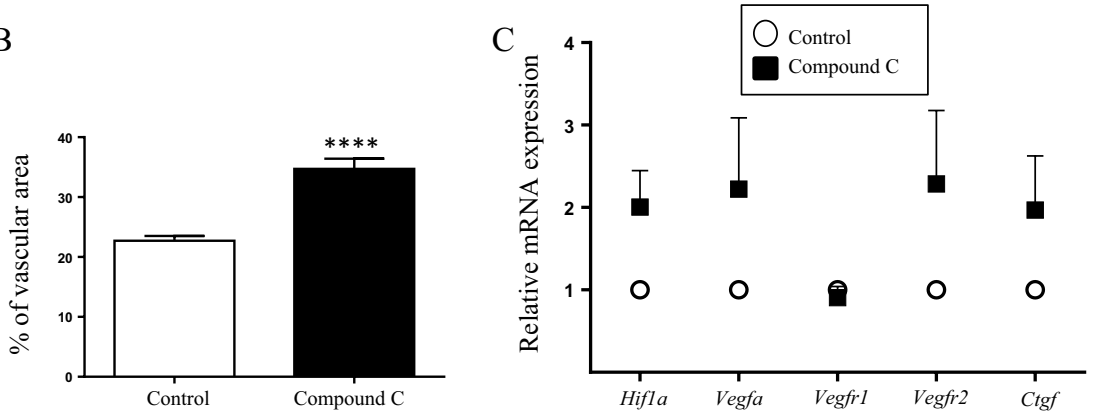

Figure 4 AMPK inhibition increases mRNA expression and strengthens vascular development in vivo. (A) Grafts with immunohistochemistry staining for $\mathrm{TH}$ and CD31 antibodies after CLARITY processing (left panels) and staining with CD31 antibody in endothelial cells only (right panels). Paired ovaries from 10-day-old mice were cultured with vehicle or $10 \mu \mathrm{M}$ Compound $\mathrm{C}$ for $1 \mathrm{~h}$ before grafting into adult hosts treated daily with FSH for 4 days. The hollow arrow indicates the primordial and primary follicles, whereas the solid arrow indicates preovulatory follicles. (B) Vascular area percentage of grafted ovaries was calculated using ImageJ software $\left(n=10 ;\right.$ mean \pm S.E.M.). ${ }^{* * * * P}<0.0001$. (C) Different mRNA levels (Hif1a, Vegfa, Vegfr 1, Vegfr2 and Ctgf) measured in 10-day-old grafted ovaries. Paired ovaries were collected after treatment with $10 \mu \mathrm{M}$

Compound $\mathrm{C}$ or vehicle. The relative mRNA expression from the control group was used as the baseline in the graph (1.0), and Actb expression was used to normalize mRNA levels $(n=3$; mean \pm S.E.M.; $P<0.05)$.
(Xu 2005, Holmes et al. 2007). Therefore, increased Vegfr2 mRNA levels in treated ovaries may be a consequence of increased Vegfa expression in ovarian cells. This finding offered indirect proof that AMPK inhibition stimulated ovarian angiogenesis and follicular development.

CTGF is a matricellular protein that plays important roles in cell adhesion, migration, proliferation, angiogenesis and other processes (Hall-Glenn \& Lyons 2011, Jun \& Lau 2011, Kubota \& Takigawa 2011). It has been confirmed that the increase of CTGF in Hippo signaling indicates cell growth, survival and proliferation in ovaries in turn (Kawamura et al. 2013), and our preliminary data have exhibited that YAP expression increased in Compound C-treated nuclei of oocytes (Supplementary Fig. 3), which means that YAP proteins had gone into nuclei and will interact with gene promoters to increase the expression of downstream CCN growth factors, including CTGF (Pan 2007). Thus, we chose this most representative gene, CTGF, to test in our experiments. Previous studies have demonstrated that AMPK activation decreased YAPdependent Ctgf expression (DeRan et al. 2014, Mo et al. 2015). However, our results showed that Ctgf expression increased in ovaries treated with the AMPK inhibitor Compound $\mathrm{C}$ in in vitro culture, in vivo grafting and in situ intrabursal injection experiments. These findings demonstrated that AMPK inhibition increased Ctgf expression in mammalian ovaries and offered insight into another mechanism associated with follicle growth. In consequence, our model indicates the mechanism of AMPK inhibition in promoting follicle proliferation as shown in Fig. 6.

Previous methods for primordial follicle activation included in vitro culture involving combined treatment with a phosphatase and tensin homolog inhibitor and a PI3K-activating peptide (Jagarlamudi et al. 2009, Li et al. 2010), treatment with an mTOR activator (Cheng et al. 2015) or dissection of the ovary into small pieces to disrupt Hippo signaling (Kawamura et al. 2013). Our results demonstrated that AMPK inhibition could also promote follicle development and angiogenesis 
A

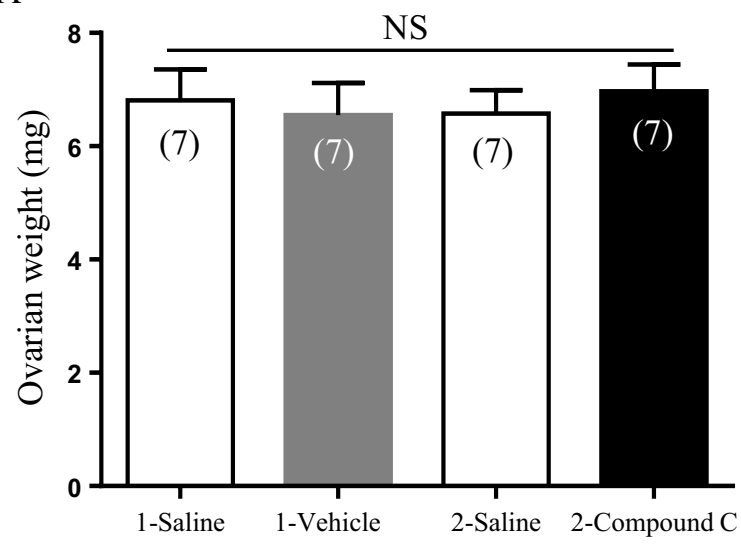

C

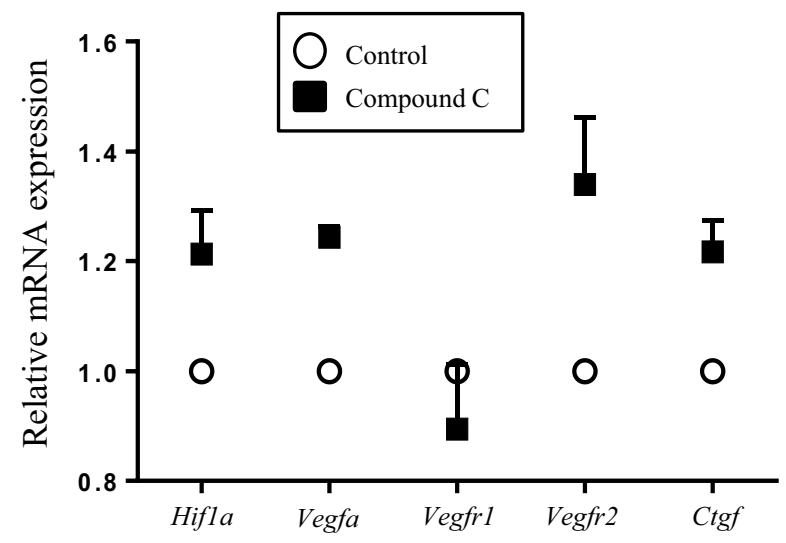

E

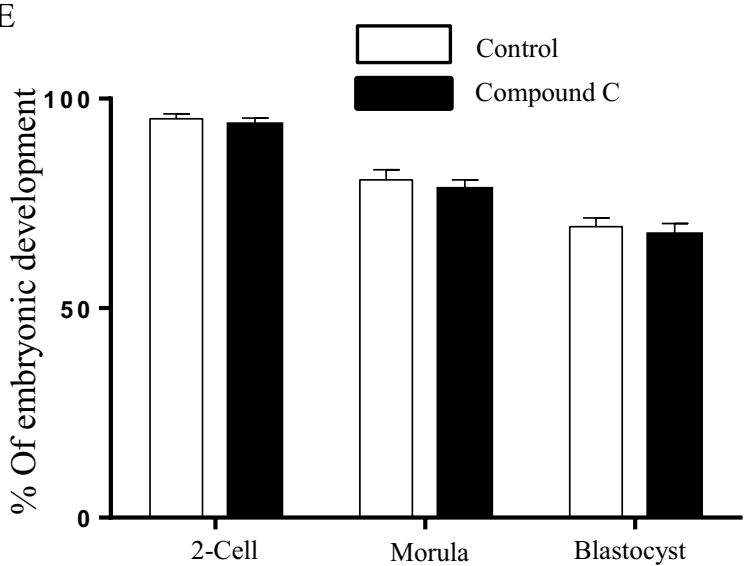

B

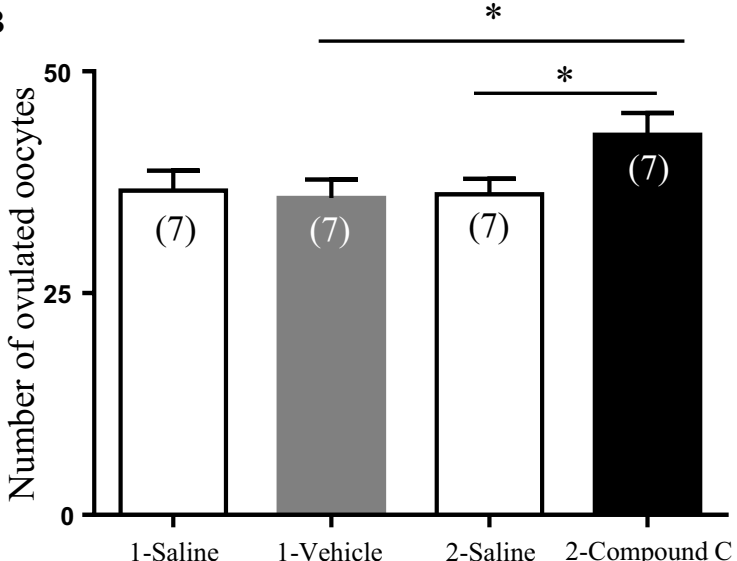

D
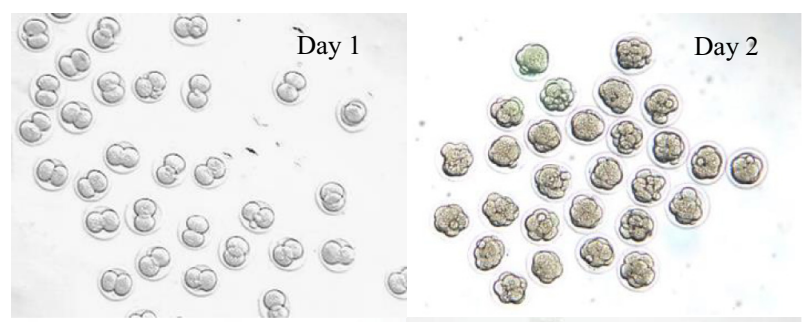

Day 3

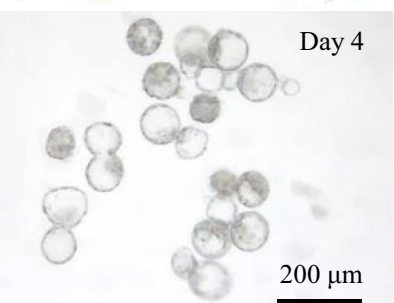

F

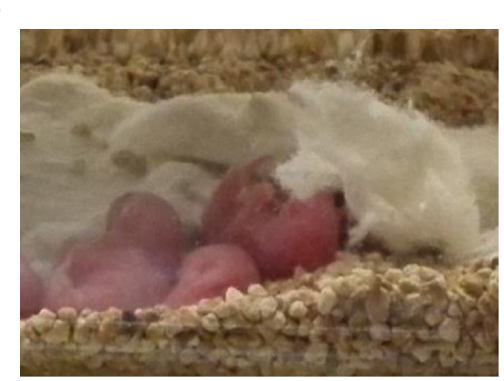

Figure 5 AMPK inhibition increases ovulated oocytes and mRNA expression in 3-week-old mice after in situ injection of Compound C followed by gonadotropin stimulation and leads to healthy pups. (A) Fourteen 3-week-old mice were randomly separated into two groups for ovarian intrabursal injection of $10 \mu \mathrm{L}$ saline on the left side and vehicle (control) or $50 \mathrm{ng} / 10 \mu \mathrm{L}$ Compound $\mathrm{C}$ (treatment) on the right side, followed by immediate injection with $5 \mathrm{IU}$ eCG and then $5 \mathrm{IU}$ hCG after $48 \mathrm{~h}$. Ovarian weight was determined after 16 h $(n=7 ;$ mean \pm S.E.M.). (B) The number of ovulated oocytes from in situ injection-treated ovaries ( $n=7$; mean \pm S.E.M.). ${ }^{*} P<0.05$. (C) mRNA expression profiles (Hif1a, Vegfa, Vegfr1, Vegfr2 and Ctgf) in ovaries treated with DMSO (control) or $50 \mathrm{ng} / 10 \mu \mathrm{L}$ Compound C. mRNA expression from the vehicle group was used as the baseline in the graph (1.0), and Actb expression was used to normalize mRNA levels ( $n=3$; mean \pm S.E.M.; $P<0.001)$. (D) Early embryonic development of oocytes after Compound C treatment. (E) Percentage of oocytes developed into each embryonic stage $(n=3$; mean \pm S.E.M.). (F) Healthy pups were delivered followed by some Compound C-pretreated 2-cell stage embryos transferred into pseudopregnant hosts. 


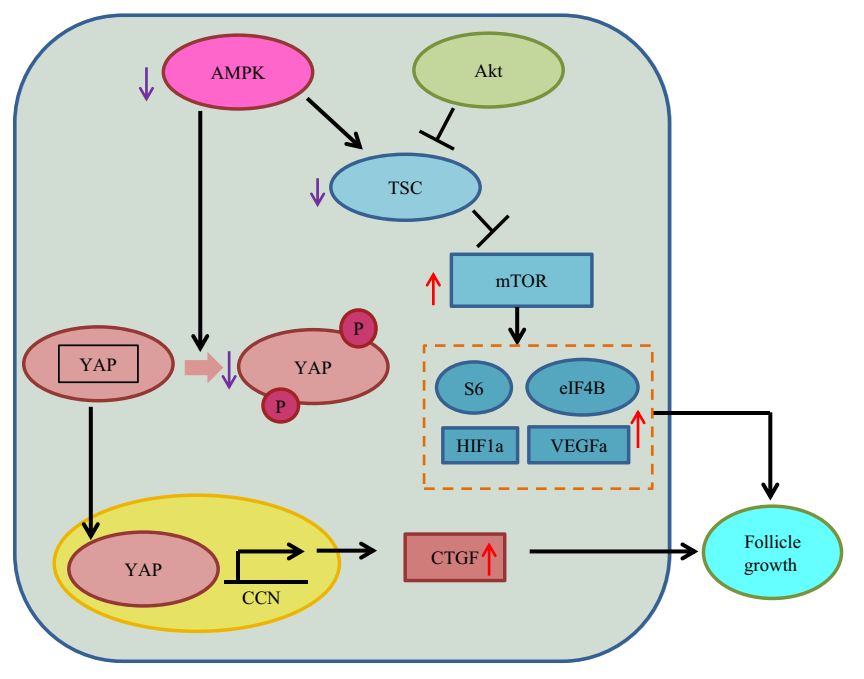

Figure $6 \mathrm{~A}$ model for follicle growth regulated by the mTOR and YAP signaling pathways and following treatment with an AMPK inhibitor. AMPK inhibition inactivates TSC2, but promotes phosphorylation and activation of mTOR downstream proteins $\mathrm{S} 6$ and elF4B, increased Hif1a and Vegfa mRNA levels, and follicle growth. In contrast, as a secondary pathway, AMPK inhibition also results in YAP localization to the nucleus where it promotes Ctgf expression, which subsequently stimulates follicle growth.

in mammalian ovaries via in vitro, in vivo or in situ treatment through the AMPK-mTOR (mTOR activation) or AMPK-CTGF pathway. Moreover, the oocytes gained from ovaries in vitro pretreated with the mTOR activator (Cheng et al. 2015) or in situ pretreated with AMPK inhibitor in our experiments were subsequently fertilized and resulted in healthy mouse offspring. These findings implied that AMPK inhibitors might potentially constitute a therapeutic method to promote ovary activation. Furthermore, current ovarian activation protocols all require removal of the ovaries for in vitro treatment procedures due to drug toxicity or the need for ovarian dissection. This requires patients with ovarian insufficiency to undergo an invasive procedure to gain usable oocytes. However, our results showed that in situ injection of Compound $\mathrm{C}$ resulted in ovarian activation in live mice, leading to healthy pups. This could be a clue that we may activate human oocytes in situ without invasive procedures someday in the future.

This study has some limitations. First, though we gained healthy pups from in situ pretreated ovaries, we did not perform additional experiments on oocytes obtained from grafted ovaries; therefore, we cannot completely confirm the function of oocytes treated with Compound C. Additionally, the AMPK inhibitor was not tested on human ovarian tissue, precluding our recommending direct application of these results to human clinical practice.

In conclusion, we showed that treatment with AMPK inhibitor resulted in the activation of the mTOR signaling pathway, increases in Ctgf expression in mouse ovaries, stimulation of follicle development, promotion of ovarian angiogenesis for ovary growth, leading to the delivery of healthy pups in in situ treatment model. This study provided some very early evidence supporting the use of AMPK inhibitors as potential therapeutic agents for patients exhibiting ovarian insufficiency to possibly improve fertility. Further studies are needed in Compound C-pretreated grafted mouse ovaries and human subjects to verify the health and efficacy of ovulated oocytes, as well as their ability to be fertilized, leading to viable offspring.

\section{Supplementary data}

This is linked to the online version of the paper at http://dx.doi. org/10.1530/REP-16-0577.

\section{Declaration of interest}

The authors declare that there is no conflict of interest that could be perceived as prejudicing the impartiality of the research reported.

\section{Funding}

This research did not receive any specific grant from any funding agency in the public, commercial or not-for-profit sector.

\section{Acknowledgements}

The authors thank Prof. Aaron J W Hsueh for all the advice, help, support and encouragement. They also thank Cell Science Imaging Core facility, Stanford University (supported by Award Number S10RR02557401 from the National Center for Research Resources) for imaging analyses and technical help by Yanhong Yu, Linlin Jiang and Trisha Shang.

\section{References}

Adhikari D, Flohr G, Gorre N, Shen Y, Yang H, Lundin E, Lan Z, Gambello MJ \& Liu K 2009 Disruption of Tsc2 in oocytes leads to overactivation of the entire pool of primordial follicles. Molecular Human Reproduction 15 765-770. (doi:10.1093/molehr/gap092)

Adhikari D, Zheng W, Shen Y, Gorre N, Hamalainen T, Cooney AJ, Huhtaniemi I, Lan ZJ \& Liu K 2010 Tsc/mTORC1 signaling in oocytes governs the quiescence and activation of primordial follicles. Human Molecular Genetics 19 397-410. (doi:10.1093/hmg/ddp483)

Bond J \& Beynon R 1995 The astacin family of metalloendopeptidases. Protein Science 4 1247-1261. (doi:10.1002/pro.5560040701)

Canty-Laird E, Carre GA, Mandon-Pepin B, Kadler KE \& Fabre S 2010 First evidence of bone morphogenetic protein 1 expression and activity in sheep ovarian follicles. Biology of Reproduction 83 138-146. (doi:10.1095/biolreprod.109.082115)

Cheng Y, Kim J, Li XX \& Hsueh AJ 2015 Promotion of ovarian follicle growth following mTOR activation: synergistic effects of AKT stimulators. PLOS ONE 10 e0117769. (doi:10.1371/journal.pone.0117769)

Choi KH, Joo BS, Sun ST, Park MJ, Son JB, Joo JK \& Lee KS 2012 Administration of visfatin during superovulation improves developmental competency of oocytes and fertility potential in aged female mice. 
Fertility and Sterility 97 1234-1241.e1231-1233. (doi:10.1016/j. fertnstert.2012.02.032)

Chung K, Wallace J, Kim SY, Kalyanasundaram S, Andalman AS Davidson TJ, Mirzabekov JJ, Zalocusky KA, Mattis J, Denisin AK et al. 2013 Structural and molecular interrogation of intact biological systems. Nature 497 332-337. (doi:10.1038/nature12107)

Dai RY, Zhao XF, Li J, Chen R, Luo ZL, Yu LX, Chen SK, Zhang CY, Duan CY, Liu YP et al. 2013 Implication of transcriptional repression in compound C-induced apoptosis in cancer cells. Cell Death and Disease 4 e883. (doi:10.1038/cddis.2013.419)

de Winter P, Leoni P \& Abraham D 2008 Connective tissue growth factor: structure-function relationships of a mosaic, multifunctional protein. Growth Factors 26 80-91. (doi:10.1080/08977190802025602)

DeRan M, Yang J, Shen CH, Peters EC, Fitamant J, Chan P, Hsieh M, Zhu S, Asara JM, Zheng B et al. 2014 Energy stress regulates hippoYAP signaling involving AMPK-mediated regulation of angiomotin-like 1 protein. Cell Reports 9 495-503. (doi:10.1016/j.celrep.2014.09.036)

Fauser BC \& Van Heusden AM 1997 Manipulation of human ovarian function: physiological concepts and clinical consequences. Endocrine Reviews 18 71-106. (doi:10.1210/edrv.18.1.0290)

Flaws JA, Abbud R, Mann RJ, Nilson JH \& Hirshfield AN 1997 Chronically elevated luteinizing hormone depletes primordial follicles in the mouse ovary. Biology of Reproduction 57 1233-1237.

Flesken-Nikitin A, Choi KC, Eng JP, Shmidt EN \& Nikitin AY 2003 Induction of carcinogenesis by concurrent inactivation of p53 and Rb1 in the mouse ovarian surface epithelium. Cancer Research 63 3459-3463.

Fukagawa M, Suzuki N, Hogan B \& Jones C 1994 Embryonic expression of mouse bone morphogenetic protein-1 (BMP-1), which is related to the drosophila dorsoventral gene tolloid and encodes a putative astacin metalloendopeptidase. Developmental Biology 163 175-183. (doi:10.1006/dbio.1994.1133)

Halder G \& Johnson RL 2011 Hippo signaling: growth control and beyond. Development 138 9-22. (doi:10.1242/dev.045500)

Hall-Glenn F \& Lyons KM 2011 Roles for CCN2 in normal physiological processes. Cellular and Molecular Life Sciences 68 3209-3217. (doi:10.1007/s00018-011-0782-7)

Hansen CG, Moroishi T \& Guan KL 2015 YAP and TAZ: a nexus for Hippo signaling and beyond. Trends in Cell Biology 25 499-513. (doi:10.1016/j. tcb.2015.05.002)

Hergovich A 2012 Mammalian Hippo signalling: a kinase network regulated by protein-protein interactions. Biochemical Society Transactions $\mathbf{4 0}$ 124-128. (doi:10.1042/BST20110619)

Holbourn KP, Acharya KR \& Perbal B 2008 The CCN family of proteins: structure-function relationships. Trends in Biochemical Sciences 33 461-473. (doi:10.1016/j.tibs.2008.07.006)

Holmes K, Roberts OL, Thomas AM \& Cross MJ 2007 Vascular endothelial growth factor receptor-2: structure, function, intracellular signalling and therapeutic inhibition. Cell Signaling 19 2003-2012. (doi:10.1016/j. cellsig.2007.05.013)

Hsueh AJ 2014 Fertility: the role of mTOR signaling and KIT ligand. Current Biology 24 R1040-R1042. (doi:10.1016/j.cub.2014.09.033)

Hsueh AJ, Adashi EY, Jones PB \& Welsh TH Jr 1984 Hormonal regulation of the differentiation of cultured ovarian granulosa cells. Endocrine Reviews 5 76-127. (doi:10.1210/edrv-5-1-76)

Huang L, Wang ZB, Jiang ZZ, Hu MW, Lin F, Zhang QH, Luo YB, Hou Y, Zhao Y, Fan HY et al. 2013 Specific disruption of Tsc1 in ovarian granulosa cells promotes ovulation and causes progressive accumulation of corpora lutea. PLoS ONE 8 e54052. (doi:10.1371/ journal.pone.0054052)

Jagarlamudi K, Liu L, Adhikari D, Reddy P, Idahl A, Ottander U, Lundin E \& Liu K 2009 Oocyte-specific deletion of Pten in mice reveals a stagespecific function of PTEN/PI3K signaling in oocytes in controlling follicular activation. PLOS ONE 4 e6186. (doi:10.1371/journal. pone.0006186)

Jiang ZZ, Hu MW, Ma XS, Schatten H, Fan HY, Wang ZB \& Sun QY 2016 LKB1 acts as a critical gatekeeper of ovarian primordial follicle pool. Oncotarget 7 5738-5753. (doi:10.18632/oncotarget.6792)

Joo JK, Joo BS, Kim SC, Choi JR, Park SH \& Lee KS 2010 Role of leptin in improvement of oocyte quality by regulation of ovarian angiogenesis. Animal Reproduction Science 119 329-334. (doi:10.1016/j. anireprosci.2010.02.002)
Jun JI \& Lau LF 2011 Taking aim at the extracellular matrix: CCN proteins as emerging therapeutic targets. Nature Reviews Drug Discovery 10 945-963. (doi:10.1038/nrd3599)

Kawamura K, Cheng Y, Suzuki N, Deguchi M, Sato Y, Takae S, Ho CH, Kawamura N, Tamura M, Hashimoto S et al. 2013 Hippo signaling disruption and Akt stimulation of ovarian follicles for infertility treatment. PNAS 110 17474-17479. (doi:10.1073/pnas.1312830110)

Kayampilly PP \& Menon KM 2009 Follicle-stimulating hormone inhibits adenosine 5'-monophosphate-activated protein kinase activation and promotes cell proliferation of primary granulosa cells in culture through an Akt-dependent pathway. Endocrinology 150 929-935. (doi:10.1210/ en.2008-1032)

Kayampilly PP \& Menon KMJ 2012 AMPK activation by dihydrotestosterone reduces $\mathrm{FSH}$-stimulated cell proliferation in rat granulosa cells by inhibiting ERK signaling pathway. Endocrinology 153 2831-2838. (doi:10.1210/en.2011-1967)

Kim E-K, Miller I, Aja S, Landree LE, Pinn M, Mc JFadden, Kuhajda FP, Moran TH \& Ronnett GV 2004 C75, a fatty acid synthase inhibitor, reduces food intake via hypothalamic AMP-activated protein kinase. Journal of Biological Chemistry 279 19970-19976. (doi:10.1074/jbc. M402165200)

Kubota S \& Takigawa M 2011 The role of CCN2 in cartilage and bone development. Journal of Cell Communication and Signaling 5 209-217. (doi:10.1007/s12079-011-0123-5)

Lei X, Cui K, Li Z, Su J, Jiang J, Zhang H, Liu Q \& Shi D 2016 BMP-1 participates in the selection and dominance of buffalo follicles by regulating the proliferation and apoptosis of granulosa cells. Theriogenology $\mathbf{8 5}$ 999-1012. (doi:10.1016/j.theriogenology.2015.11.011)

Li J, Kawamura K, Cheng Y, Liu S, Klein C, Liu S, Duan EK \& Hsueh AJ 2010 Activation of dormant ovarian follicles to generate mature eggs. PNAS 107 10280-10284. (doi:10.1073/pnas.1001198107)

Lin J, Maeda R, Ong R, Kim J, Lee L, Kung H \& Maéno M 1997 XBMP-1B (Xtld), a Xenopus homolog of dorso-ventral polarity gene in Drosophila, modifies tissue phenotypes of ventral explants. Development Growth and Differentiation 39 43-51. (doi:10.1046/j.1440-169X.1997.00006.x)

Liu X, Chhipa RR, Nakano I \& Dasgupta B 2014 The AMPK inhibitor compound $\mathrm{C}$ is a potent AMPK-independent antiglioma agent. Molecular Cancer Therapeutics 13 596-605. (doi:10.1158/1535-7163.MCT-130579)

Livak KJ \& Schmittgen TD 2001 Analysis of relative gene expression data using real-time quantitative PCR and the 2(-Delta Delta C(T)) method. Methods 25 402-408. (doi:10.1006/meth.2001.1262)

Maéno M, Xue Y, Wood T, Ong R \& Kung H 1993 Cloning and expression of cDNA encoding Xenopus laevis bone morphogenetic protein-1 during early embryonic development. Gene 134 257-261.

Mamane Y, Petroulakis E, LeBacquer O \& Sonenberg N 2006 mTOR, translation initiation and cancer. Oncogene 25 6416-6422. (doi:10.1038/sj.onc.1209888)

Manning BD, Tee AR, Logsdon MN, Blenis J \& Cantley LC 2002 Identification of the tuberous sclerosis complex-2 tumor suppressor gene product tuberin as a target of the phosphoinositide 3-kinase/akt pathway. Molecular Cell 10 151-162.

McCullough LD, Zeng Z, Li H, Landree LE, Mc JFadden \& Ronnett GV 2005 Pharmacological inhibition of AMP-activated protein kinase provides neuroprotection in stroke. Journal of Biological Chemistry 280 20493-20502. (doi:10.1074/jbc.M409985200)

Mo JS, Meng Z, Kim YC, Park HW, Hansen CG, Kim S, Lim DS \& Guan KL 2015 Cellular energy stress induces AMPK-mediated regulation of YAP and the Hippo pathway. Nature Cell Biology 17 500-510. (doi:10.1038/ ncb3111)

Nishimura R \& Okuda K 2010 Hypoxia is important for establishing vascularization during corpus luteum formation in cattle. Journal of Reproduction and Development 56 110-116.

Novikova DS, Garabadzhiu AV, Melino G, Barlev NA \& Tribulovich VG 2015 AMP-activated protein kinase: Structure, function, and role in pathological processes. Biochemistry 80 127-144. (doi:10.1134/ s0006297915020017)

Pan D 2007 Hippo signaling in organ size control. Genes and Development 21 886-897. (doi:10.1101/gad.1536007)

Park MJ, Park SH, Lee SK, Moon SE, Moon HS \& Joo BS 2011 Expression of SDF-1alpha and leptin, and their effect on expression of angiogenic 
factors in mouse ovaries. Clinical and Experimental Reproductive Medicine 38 135-141. (doi:10.5653/cerm.2011.38.3.135)

Park MJ, Park SH, Moon SE, Koo JS, Moon HS \& Joo BS 2013 Decreased expression of inhibitor of DNA-binding (Id) proteins and vascular endothelial growth factor and increased apoptosis in ovarian aging. Development and Reproduction 17 17-24. (doi:10.12717/ DR.2013.17.1.017)

Perl A 2015 mTOR activation is a biomarker and a central pathway to autoimmune disorders, cancer, obesity, and aging. Annals of the New York Academy of Sciences 1346 33-44. (doi:10.1111/nyas.12756)

Piccolo S, Dupont S \& Cordenonsi M 2014 The biology of YAP/TAZ: hippo signaling and beyond. Physiological Reviews 94 1287-1312. (doi:10.1152/physrev.00005.2014)

Reddy P, Liu L, Adhikari D, Jagarlamudi K, Rajareddy S, Shen Y, Du C, Tang W, Hamalainen T, Peng SL et al. 2008 Oocyte-specific deletion of Pten causes premature activation of the primordial follicle pool. Science 319 611-613. (doi:10.1126/science.1152257)

Reynolds S, Zhang D, Puzas J, O'Keefe R, Rosier R \& Reynolds P 2000 Cloning of the chick BMP1/Tolloid cDNA and expression in skeletal tissues. Gene 248 233-243.

Richards JS 1980 Maturation of ovarian follicles: actions and interactions of pituitary and ovarian hormones on follicular cell differentiation. Physiological Reviews 60 51-89.

Rico C, Dodelet-Devillers A, Paquet M, Tsoi M, Lapointe E, Carmeliet P \& Boerboom D 2014 HIF1 activity in granulosa cells is required for FSH-regulated Vegfa expression and follicle survival in mice. Biology of Reproduction 90 135. (doi:10.1095/biolreprod.113.115634)

Riera MF, Regueira M, Galardo MN, Pellizzari EH, Meroni SB \& Cigorraga SB 2012 Signal transduction pathways in FSH regulation of rat Sertoli cell proliferation. American Journal of Physiology: Endocrinology and Metabolism 302 E914-923. (doi:10.1152/ajpendo.00477.2011)

Scotti L, Irusta G, Abramovich D, Tesone M \& Parborell F 2011 Administration of a gonadotropin-releasing hormone agonist affects corpus luteum vascular stability and development and induces luteal apoptosis in a rat model of ovarian hyperstimulation syndrome. Molecular and Cellular Endocrinology 335 116-125. (doi:10.1016/j. mce.2011.01.002)

Shackelford DB \& Shaw RJ 2009 The LKB1-AMPK pathway: metabolism and growth control in tumour suppression. Nature Reviews Cancer $\mathbf{9}$ 563-575. (doi:10.1038/nrc2676)

Shibuya M 2006 Vascular endothelial growth factor receptor-1 (VEGFR-1/ Flt-1): a dual regulator for angiogenesis. Angiogenesis 9 225-230; discussion 231. (doi:10.1007/s10456-006-9055-8)

Takahara K, Lee S, Wood S \& Greenspan D 1995 Structural organization and genetic localization of the human bone morphogenetic protein 1/mammalian tolloid gene. Genomics 29 9-15. (doi:10.1006/ geno.1995.1209)

Tang YC, Williams BR, Siegel JJ \& Amon A 2011 Identification of aneuploidy-selective antiproliferation compounds. Cell 144 499-512. (doi:10.1016/j.cell.2011.01.017)

Tomer R, Ye L, Hsueh B \& Deisseroth K 2014 Advanced CLARITY for rapid and high-resolution imaging of intact tissues. Nature Protocols $\mathbf{9}$ 1682-1697. (doi:10.1038/nprot.2014.123)

Vitt UA, EA McGee, Hayashi M \& Hsueh AJ 2000 In vivo treatment with GDF-9 stimulates primordial and primary follicle progression and theca cell marker CYP17 in ovaries of immature rats. Endocrinology 141 3814-3820. (doi:10.1210/endo.141.10.7732)
Will MA, Palaniappan M, Peegel H, Kayampilly P \& Menon KM 2012 Metformin: direct inhibition of rat ovarian theca-interstitial cell proliferation. Fertility and Sterility 98 207-214. (doi:10.1016/j. fertnstert.2012.04.010)

Wu L, Zhang Z, Pan X \& Wang Z 2015 Expression and contribution of the HIF-1alpha/VEGF signaling pathway to luteal development and function in pregnant rats. Molecular Medicine Reports 12 7153-7159. (doi:10.3892/mmr.2015.4268)

Xu QB 2005 Endothelial progenitor cells in angiogenesis. Sheng Li Xue Bao 57 1-6.

Yalu R, Oyesiji AE, Eisenberg I, Imbar T \& Meidan R 2015 HIF1Adependent increase in endothelin 2 levels in granulosa cells: role of hypoxia, LH/CAMP, and reactive oxygen species. Reproduction 149 11-20. (doi:10.1530/REP-14-0409)

Yamamoto S, Konishi I, Tsuruta Y, Nanbu K, Mandai M, Kuroda H, Matsushita K, Hamid AA, Yura Y \& Mori T 1997 Expression of vascular endothelial growth factor (VEGF) during folliculogenesis and corpus luteum formation in the human ovary. Gynecological Endocrinology 11 371-381.

Yi D, Hou Y, Wang L, Ouyang W, Long M, Zhao D, Ding B, Liu Y \& Wu G 2015 I-Glutamine enhances enterocyte growth via activation of the mTOR signaling pathway independently of AMPK. Amino Acids 47 65-78. (doi:10.1007/s00726-014-1842-8)

Yu PB, Hong CC, Sachidanandan C, Babitt JL, Deng DY, Hoyng SA, Lin HY, Bloch KD \& Peterson RT 2007 Dorsomorphin inhibits BMP signals required for embryogenesis and iron metabolism. Nature Chemical Biology 4 33-41. (doi:10.1038/nchembio.2007.54)

Zhang H \& Liu K 2015 Cellular and molecular regulation of the activation of mammalian primordial follicles: somatic cells initiate follicle activation in adulthood. Human Reproduction Update 21 779-786. (doi:10.1093/ humupd/dmv037)

Zhang L, Yue T \& Jiang J 2009 Hippo signaling pathway and organ size control. Fly 3 68-73.

Zhang Y, Xu F, Liang H, Cai M, Wen X, Li X \& Weng J 2015 Exenatide inhibits the growth of endometrial cancer Ishikawa xenografts in nude mice. Oncology Reports 35 1340-1348. (doi:10.3892/or.2015.4476)

Zhao P, Dou Y, Chen L, Li L, Wei Z, Yu J, Wu X, Dai Y \& Xia Y 2015 SC-III3, a novel scopoletin derivative, induces autophagy of human hepatoma HepG2 cells through AMPK/mTOR signaling pathway by acting on mitochondria. Fitoterapia 104 31-40. (doi:10.1016/j.fitote.2015.05.002)

Zhou G, Myers R, Li Y, Chen Y, Shen X, Fenyk-Melody J, Wu M, Ventre J, Doebber T, Fujii $\mathbf{N}$ et al. 2001 Role of AMP-activated protein kinase in mechanism of metformin action. Journal of Clinical Investigation $\mathbf{1 0 8}$ 1167-1174. (doi:10.1172/jci13505)

Zhou Y, He X, Chen Y, Huang Y, Wu L \& He J 2015 Exendin-4 attenuates cardiac hypertrophy via AMPK/mTOR signaling pathway activation. Biochemical and Biophysical Research Communications 468 394-399. (doi:10.1016/j.bbrc.2015.09.179)

Received 20 October 2016

First decision 10 November 2016

Revised manuscript received 31 January 2017

Accepted 28 February 2017 